\title{
Three Dimensional Microstructural Characterization of Nanoscale Precipitates in AA7075-T651 by Focused Ion Beam (FIB) Tomography
}

\author{
Sudhanshu S. Singh ${ }^{1 \#}$, Jose J. Loza ${ }^{1}$, Arno P. Merkle ${ }^{2}$, and Nikhilesh Chawla ${ }^{1}$ *
}

\footnotetext{
${ }^{1}$ Materials Science and Engineering, Arizona State University, Tempe, AZ 85287-6106

${ }^{2}$ Carl Zeiss X-ray Microscopy, Inc., Pleasanton, CA USA
}

Submitted in revised form to:

\section{Materials Characterization}

2016

*Corresponding author: nchawla@asu.edu, 480-965-2402

\# Current address: Assistant Professor, Department of Materials Science and Engineering, Indian Institute of Technology, Kanpur, 208016, Uttar Pradesh, India 


\begin{abstract}
The size and distribution of precipitates in Al 7075 alloys affects both the mechanical and corrosion behavior (including stress corrosion cracking and fatigue corrosion) of the alloy. Three dimensional (3D) quantitative microstructural analysis of $\mathrm{Al} 7075$ in the peak aged condition (T651) allows for a better understanding of these behaviors. In this study, Focused ion beam (FIB) tomography was used to characterize the microstructure in three dimensions. Analysis of grains and precipitates was performed in terms of volume, size, and morphology. It was found that the precipitates at the grain boundaries are larger in size, higher in aspect ratios and maximum Feret diameter compared to the precipitates inside the grains, due to earlier nucleation of the precipitates at the grain boundaries. Our data on the precipitates at the interface between grains and $\mathrm{Mg}_{2} \mathrm{Si}$ inclusion show that the surfaces of inclusion (impurity) particles can serve as a location for heterogeneous nucleation of precipitates.
\end{abstract}

Keywords: AA 7075-T651, Precipitates, Grains, Focused Ion Beam (FIB) 


\begin{abstract}
The size and distribution of precipitates in Al 7075 alloys affects both the mechanical and corrosion behavior (including stress corrosion cracking and fatigue corrosion) of the alloy. Three dimensional (3D) quantitative microstructural analysis of $\mathrm{Al} 7075$ in the peak aged condition (T651) allows for a better understanding of these behaviors. In this study, Focused ion beam (FIB) tomography was used to characterize the microstructure in three dimensions. Analysis of grains and precipitates was performed in terms of volume, size, and morphology. It was found that the precipitates at the grain boundaries are larger in size, higher in aspect ratios and maximum Feret diameter compared to the precipitates inside the grains, due to earlier nucleation of the precipitates at the grain boundaries. Our data on the precipitates at the interface between grains and $\mathrm{Mg}_{2} \mathrm{Si}$ inclusion show that the surfaces of inclusion (impurity) particles can serve as a location for heterogeneous nucleation of precipitates.
\end{abstract}

Keywords: AA 7075-T651, Precipitates, Grains, Focused Ion Beam (FIB) 


\section{Introduction}

7075 aluminum alloys are used extensively due to their high strength-to-weight ratio $[1,2]$. The microstructure of the alloy at different length scales is shown in Figure 1. It consists of a polycrystalline aggregate of grains as well as second phase particles. The second phase particles can essentially be divided into inclusions (also called constituent particles) and precipitates, whose dimensions are on the order of micrometers and nanometers, respectively. These second phase particles are known to affect the mechanical and corrosion properties of $\mathrm{Al}$ alloys [3, 4]. Inclusions are known to be formed during casting from impurities. 3D microstructural characterization of inclusions in this alloy using $\mathrm{x}$-ray synchrotron tomography has been performed in previous work [5].

The nanoscale precipitates are formed when the alloy is either naturally aged or artificially aged following a solution heat treatment. It has been widely accepted that the precipitation sequence in AA7075 is as follows: Supersaturated solid solution $\rightarrow$ GP zones $\rightarrow \eta$ ' $\rightarrow \eta[6,7]$. However, some have argued that the precipitation sequence follows this sequence: Supersaturated solid solution $\rightarrow$ GP zones $\rightarrow \eta^{\prime} \rightarrow\left(\eta_{\mathrm{p}} \rightarrow\right) \eta[8,9]$. Although the yield strength is the highest for peak-aged temper, it is also more susceptible to stress corrosion cracking than over-aged temper [10]. The variation in mechanical and corrosion properties has been attributed to the size, shape, and distribution of precipitates in the alloy microstructure $[11,12]$. Therefore, in order to understand the monotonic and corrosion properties of the alloy, it is important to quantify the three dimensional (3D) structure of the precipitates in the alloy.

Several studies have been performed on the size and distribution of precipitates in $\mathrm{Al}$ alloys $[10,13-20]$. To the best of our knowledge, to date the characterization of large volumes of precipitates in AA7075 has been performed only in two dimensions (2D). Most of these studies have used transmission electron microscopy (TEM), which provides very high resolution images. 
However, due to the small area considered, the results usually cannot be considered a statistically representative sample of the materials. Birbills et al. [21] used 2D stereology along with TEM to characterize and quantify size of precipitates. Recently, other techniques such as amplitudemodulated atomic force microscopy (AM-AFM) along with TEM have been used to quantify the precipitate structure [13], while differential scanning calorimetry (DSC) [12, 22-23] and X-ray scattering techniques [24] have been used to study the formation and dissolution of precipitates in Al 7075 alloys. The shape of $\eta$ ' precipitates has been shown to be platelike [22, 25-27], whereas $\eta$ is formed in either plate or rod form $[10,22,25-26]$. The size of $\eta$ and $\eta$ ' precipitates from all these studies falls in the range of approximately 10-300 $\mathrm{nm}$.

Experimental techniques for 3D microstructural characterization include atom probe tomography (APT) [28], electron tomography [29], focused ion beam (FIB) tomography [30], serial sectioning followed by optical microscopy [31], and x-ray tomography [32]. Serial sectioning followed by optical microscopy and x-ray tomography can be used to study large volumes of material, resulting in statistically significant information, but due to limited resolution, these techniques cannot be used for precipitates. 3D atom probe tomography and electron tomography provide very high resolution images, but only very small volumes can be analyzed. Although destructive in nature, focused ion beam (FIB) tomography is well suited to study the precipitates in Al alloys. It provides high resolution images (on the order of $10 \mathrm{~nm}$ ) along with a large enough volume to provide statistically accurate information of nano-scale precipitates. FIB tomography has already been successfully utilized to characterize the microstructure in Al-SiC nanolaminates [33], Pb-free solders [34, 35], and superalloys [36, 37].

The present work is a follow up to our recent work on correlative tomography [38]. Non-destructive XRM (X-ray microscopy) data acquisition was used to identify inclusions (larger in size as shown in Fig. 1) and associated pores, and then to inform and automate FIBSEM (Focused ion beam-scanning electron microscopy) tomography in the same area to 
visualize precipitate structures (at much smaller length-scale). This approach may be extended to multiple FIB-SEM tomography sites, greatly expanding FIB utilization via the navigation workflow of Atlas 5 and XRM data $[38,39]$. Furthermore, the preceding non-destructive XRM analysis may, importantly, be extended to time-dependent (4D) or in situ conditions to quantify the evolution of a structure (processing, aging, corrosion, etc.) prior to inspection by FIB-SEM tomography at defined locations. Recently, we have visualized and quantified the microstructure of inclusions and pores in 3D and have also obtained their mechanical and corrosion properties from the same plate of AA7075 [5, 40, 41].

In this study, we have obtained the $3 \mathrm{D}$ microstructure of precipitates in an aluminum alloy AA7075-T651. The volume, size, and distribution of precipitates were visualized and quantified both in the grain boundaries and inside the grains. For the first time, a large volume was studied using FIB tomography to obtain quantitative, statistical information on the 3D microstructure of the precipitates. We also show that large inclusion particles can serve as heterogeneous nucleation sites for precipitate formation, thus localizing precipitate formation. A knowledge of the 3D microstructure will facilitate a better understanding of the mechanical and corrosion properties of the alloy.

\section{Experimental Procedure}

The material used in this study was a commercially available 7075-T651 aluminum alloy (5.63 Zn, 2.45 Mg, $1.55 \mathrm{Cu}, 0.045 \mathrm{Si}, 0.18 \mathrm{Fe}, 0.008 \mathrm{Mn}, 0.19 \mathrm{Cr}, 0.004 \mathrm{Ni}, 0.049 \mathrm{Ti}$, and rest Al) rolled to a $2.5 \mathrm{~cm}$ thickness (Alcan rolled product, supplied by Dix Metals Inc). A small specimen $(\sim 3 \mathrm{~mm} \times 3 \mathrm{~mm} \times 4 \mathrm{~mm})$ was cut near the surface of the rolled plate. The specimen was polished to a $1 \mu \mathrm{m}$ diamond finish and then to a final finish of $0.05 \mu \mathrm{m}$ colloidal silica. 
Correlative tomography using a combination of X-ray microscopy (XRM) and FIBtomography was performed on the polished sample. The 3D XRM datasets were loaded into ZEISS Atlas 5 for alignment and registration with the 2D surface SEM images (online acquisition), upon which the XRM dataset was used to navigate the FIB-SEM to the precise region for FIB-tomography. The details of data acquisition using X-ray microscopy are provided elsewhere [38].

Atlas FIB-SEM tomography was acquired on a ZEISS Crossbeam 540 utilizing $10 \mathrm{~nm}$ isotropic voxel size and an EsB detector with SEM voltage of $1.5 \mathrm{kV}$. The collected FIB-SEM volume was approximately $18 \mu \mathrm{m} \times 8 \mu \mathrm{m}$ x $7 \mu \mathrm{m}$. The sampled volume $\left(\sim 1000 \mu \mathrm{m}^{3}\right)$ was chosen to obtain a good statistics on the size and shape of the precipitates and also not loose information of many small precipitates (increasing the volume will result in loosing information of very small precipitates). With the 3D Tomography option in ZEISS Atlas 5, the FIB was used to mill a geometric pattern of fiducial marks into the sample surface before the FIB-SEM tomography run was executed. During the tomography run, the FIB exposed and milled a crosssection of the sample, perpendicular to the sample surface. Simultaneous with this milling, the SEM imaged the cross-section face, including a cross-section of the marks previously prepared on the sample surface. From the position and configuration of these marks, the software was able to accurately measure both the position of the sample, and the distance between slices of the sample cross-section. This information was used to predictively correct the positions of the both FIB milling and SEM imaging to correct for sample drift and variability in the sample erosion rate. In this fashion, a sequence of well aligned cross-section images was produced, with consistent, measured slice thicknesses.

After acquisition, the FIB-SEM image stack was aligned and cropped in ZEISS Atlas 5 before exporting for further 3D visualization and quantification. The fine alignment of the image stack was calculated by performing a cross-correlation between adjacent slices in the stack over a 
user defined sub-region. The information from this cross-correlation was used to produce small corrections in the X-Y position of each slice to improve the overall alignment of the stack.

The stack of aligned grayscale images was analyzed and segmented using ImageJ (Bethesda, MD) and MIMICS (Materialise, Ann Arbor, MI). For the segmentation of grains, inclusion and pore, an anisotropic diffusion filter [42] was first used to increase the signal-tonoise ratio while preserving edges, followed by segmentation using a combination of Livewire (MIMICS, Materialise, Ann Arbor, MI) and ImageJ.

To segment the precipitates, the stack of images was first filtered using both a bandpass filter and anisotropic diffusion filter, and then was segmented using conventional thresholding in ImageJ. The details of segmentation process are given in next section. The segmented images were imported into Avizo ${ }^{\circledR}$ Fire (VSG, Burlington, MA) for 3D reconstruction and visualization. Quantitative analysis of the size, shape, and distribution of the precipitates was performed using Matlab and Avizo ${ }^{\circledR}$ Fire.

\section{Results and Discussion}

Figure 2 shows a back scattered electron (BSE) image of one of the 2D slices of AA7075 obtained using focused ion beam (FIB) serial sectioning. The grains are clearly visible in the image due to ion channeling contrast. Also visible is an $\mathrm{Mg}_{2} \mathrm{Si}$ inclusion and a pore associated with it. The pores are believed to be formed during rolling $[43,44]$. The formation of pores might be attributed to the presence of the hard inclusions which induce a triaxial state of stress and constraint in the matrix, and therefore contribute to the formation of pores or voids in the matrix. The small bright features along the grain boundaries and inside grains are precipitates. Figure $3 \mathrm{a}$ shows a 3D rendering of the studied volume and figure $3 \mathrm{~b}$ shows the cropped volume showing the pore associated with the inclusion. 
Image segmentation is an important and necessary process to obtain data sets that can be used for quantitative analysis. The process for image segmentation of these datasets is shown in Figures 4 (a-e). Here we can see examples of the grains, inclusions, and pores. Figure 4a is a 2D slice obtained from FIB tomography. Figure $4 \mathrm{~b}$ shows the filtered image after application of an anisotropic diffusion filter showing increase in the signal-to-noise ratio. Figures $4 \mathrm{f}$ and $4 \mathrm{~g}$ (magnified versions of the blue region in Figure 4a) show images before and after application of anisotropic diffusion filter, respectively. Figure $4 \mathrm{~g}$ shows a clear improvement in signal-to-noise ratio. Figures 4 (c-e) show the use of the Livewire technique for segmentation. This technique uses a contour line (livewire line), which traces the sharp gradient in gray scale between two objects. In this case, the gradient is between two grains. The mathematics behind the Livewire technique has been described elsewhere $[45,46]$. The technique is semi-automatic since the user selects the number of seed points on the livewire line. One can also "force" the livewire line to pass through the boundaries where a sharp gradient in gray scale is not observed. The contour is drawn on two orthogonal planes after which the software automatically contours the grain on the third orthogonal plane, as shown in Figure 4c. The magnified version of Figure $4 \mathrm{c}$ is shown in Figure 4e, where perpendicular lines, which are contour lines along grain boundary in two orthogonal planes, can clearly be seen in the third orthogonal plane. The final result is the 3D mask of the grain, as shown in Figure $4 \mathrm{~d}$.

Figure 5 shows the steps to segment the precipitates. Due to the very small size of precipitates, the Livewire technique was not suitable for segmentation and therefore a conventional thresholding technique was used. The grayscale values of some of the grains were very close to the grayscale values of the precipitates, which created a problem when using simple thresholding. Thus, the stack of images was filtered using a band pass filter. This operation increased the contrast of the precipitates and suppressed the background, as shown in Fig. 5b. The stack of images was then filtered by an anisotropic diffusion filter to increase signal-to- 
noise ratio (Fig. 5c). The combination of bandpass filter and anisotropic diffusion filter resulted in gray scale images suitable for thresholding, the result of which is shown in Fig 5d. After segmentation, the dataset had many one voxel precipitates. The segmented dataset was compared with the original gray scale images and it was found that several of them were actually noise and not precipitates. Therefore, to minimize the uncertainty of the analysis, all features having a volume of $1000 \mathrm{~nm}^{3}$ (one voxel), including actual precipitate, were removed from the analysis. All other precipitates, with volume greater than one voxel, were first compared with the original gray scale images and then taken into account for the measurements.

Figure 6 shows a 3D rendering obtained using Avizo ${ }^{\circledR}$ Fire of (a) grains, an inclusion, and a pore, (b) precipitates, and (c) all constituents. From the 3D rendering, it appears that grains are not very elongated and that the precipitates are uniformly distributed. Figure 7 shows the measured volume and sphericity distribution of the grains and Table 1 shows the corresponding quantitative analysis. A total of 25 grains were segmented to obtain quantification on grains. We would like to mention here that our main aim is to characterize the microstructure of precipitates in 3D. As mentioned in the experimental section, a large volume would have resulted in loosing information on smaller precipitates and therefore the number of grains in the studied volume is expected to be small (size of grains being microns). The sphericity $(\psi)$ of the grain is defined as [47]:

$$
\Psi=\left(\frac{36 \pi V_{g}^{2}}{A_{g}^{3}}\right)^{1 / 3}
$$

Where, $\mathrm{V}_{\mathrm{g}}$ and $\mathrm{A}_{\mathrm{g}}$ are the volume and surface area of the grains, respectively. The volume and surface area of the grains were calculated automatically in the software Avizo ${ }^{\circledR}$ Fire. As the sphericity approaches a value of one, the shape of the grain approaches that of a perfect sphere. The sphericity distribution and the average value of 0.73 indicate that the grains are not highly 
elongated, as expected due to rolling, potentially indicating that these grains are recrystallized grains. It has been shown that the variation of solute concentration, deformation condition, solutionizing temperature, etc. leads to variation in recrystallization structure in the hot rolled plate [48]. It is known that the hot rolling process increases the energy of the system by increasing the stored strain energy and so the original grains are replaced by low energy recrystallized grains [48]. The average grain size of the recrystallized grains is about $3 \mu \mathrm{m}$. The volume distribution is skewed towards smaller volumes and therefore skewness has been reported for the data on volume of grains. Skewness is a measure of the degree of asymmetry in a statistical distribution. Positive values of skewness indicate that the mean is higher than the median, while negative skewness indicates the median is higher than the mean.

The volume fraction of precipitates was $\sim 2.4 \%$. Figure 8 shows the distributions of volume, aspect ratio and Feret diameter, while Table 2 summarizes the quantitative analysis. The shape of the precipitates was quantified by the maximum Feret diameter and aspect ratio. Feret diameter is defined as the distance between two parallel tangents of the particle. Maximum Feret diameter is the maximum of all Feret diameters. Maximum and minimum Feret diameters were obtained from Avizo ${ }^{\circledR}$ Fire. The aspect ratio is defined as the ratio of maximum Feret diameter (length) to minimum Feret diameter (width). Figures 8(a-c) show that the frequency distributions of volume, aspect ratio, and maximum Feret diameter are highly skewed with higher frequency being mostly associated with smaller values. The same type of skewed distribution for equivalent diameter was observed by Garcia et al. [13] using TEM and AFM.

A closer look at the 3D rendering of precipitates (Figure 6) indicates that the precipitates with higher Feret diameter and volume are associated with grain boundaries. Therefore, we have further split our analysis into precipitates at the grain boundary and precipitates within the grain, as shown in Figure 9. The steps for separation of precipitates into grain boundaries and inside the grains are as follows: (a) a stack of images with segmented grains was obtained using Livewire 
technique (explained above). All grains were given different gray values, (b) another stack of images with segmented precipitates was obtained using conventional thresholding (explained above). All precipitates were given a single gray value, (c) a Matlab code was written to separate out grain boundary precipitates and precipitates inside the grains. The code is based on the fact that when these two stacks of images are superimposed, all voxels of a particular precipitate would have similar gray scale values if the precipitate is completely inside the grain. If the precipitate is at the grain boundary then all voxels will not have same gray values. Figure 10 shows the magnified version of four grains showing the precipitates size and shape on the grain boundaries and inside the grains. It is clear the grain boundaries precipitates are larger in size than the precipitates inside the grains. Precipitates with rod, plate and spherical shape can be seen in Figure 10. These precipitate morphologies have also been observed by others [22, 25-27]. Many precipitates appear to have other irregular shapes compared to the idealized shapes mentioned above. We believe that this might be due to variation in the local growth conditions due to grain orientation and also due to their interaction during growth. This may also be due to the rendering of small precipitates (containing few voxels). Although care was taken in segmenting and rendering of these small precipitates, the process is difficult and therefore can lead to irregularity in shape.

It is well known that grain boundaries and interphase boundaries are one of the preferred sites for heterogeneous nucleation in age-hardening aluminum alloys since they provide a low activation energy barrier for nucleation of precipitates [27, 49]. Nucleation of precipitates can also occur on dislocations and vacancies present in the matrix, however, the activation energy barrier for these sites is higher than the grain/phase boundaries and therefore there is a time lag of aging response between grain boundaries and matrix. Due to the early nucleation and faster growth (easy diffusion) at grain boundaries, the precipitates on the grain boundaries and on the phase boundaries are larger in size than the precipitates in the matrix. 
Quantitative analysis was performed to characterize the size and shape of the precipitates on the grain boundaries and inside the grains, as in shown in Table 3. It should be mentioned here that the precipitates on the boundary between grains and the $\mathrm{Mg}_{2} \mathrm{Si}$ inclusions have been included in grain boundary precipitate distribution. The average volume of precipitates on the grain boundaries is about 2.5 times the average volume of precipitates inside the grains. Interestingly the skewness values for precipitates both inside and on grain boundaries are high, i.e. $~ 6.9$, indicating that the volume distribution is skewed (towards lower volume), as shown in Figure 11.

The average values of Feret diameter and aspect ratio of precipitates on grain boundaries are higher than that of the precipitates inside grains. Although the maximum value of Feret diameter for the precipitates on the grain boundaries is much higher than that of the precipitates inside the grains ( 3.5 times), the average values are only slightly higher for those at grain boundaries (145 nm vs $114 \mathrm{~nm}$ ). This can be attributed to the higher skewed values of the distribution for grain boundary precipitates, in which about $70 \%$ of the precipitates have maximum Feret diameter of less than $100 \mathrm{~nm}$. The aspect ratio shows the same types of distribution.

In the peak-aged condition, the precipitates are mostly a combination of $\eta$ and $\eta$ ' $[7,13]$. Over the years there have been several studies on the composition and structure of these precipitates. It was believed that the composition of precipitates is $\operatorname{MgZn}_{2}$ [13, 21, 23-24]. However, it has now been shown that although the crystal structure of precipitates in $\mathrm{Cu}$ containing 7xxx series aluminum alloys is the same as $\mathrm{MgZn}_{2}$, the composition is not exactly the same. In fact, substitution of $\mathrm{Cu}$ and $\mathrm{Al}$ with $\mathrm{Zn}$ atoms occurs during aging leading to compositions such as $\mathrm{Mg}(\mathrm{ZnCu})_{2}$ and $\mathrm{Mg}(\mathrm{Zn}, \mathrm{Al}, \mathrm{Cu})_{2}$ [10, 50]. Without discussing the composition, in this paper we will denote precipitates as a combination of $\eta$ and $\eta$ '. 
As shown in Figure 12, the interface between the $\mathrm{Mg}_{2} \mathrm{Si}$ inclusion and $\mathrm{Al}$ is also a preferred site for nucleation of precipitates. It should be noted here that only a part of a single inclusion was taken into consideration for quantification because obtaining FIB tomography data of these large inclusions is extremely time consuming. A few points can be made from this data. The distributions of volume, maximum Feret diameter and aspect ratio are skewed, as shown in Figure 13. It is interesting to note that the surface of the inclusion also serves as a location for heterogeneous nucleation of precipitates. This is an important finding because it means that the presence of inclusions can influence the distribution and fraction of this type of precipitates in the material. For example, a larger fraction of high surface area inclusions would mean a large density of overaged precipitates in the microstructure because of the early nucleation of the precipitates due to heterogeneous nucleation.

\section{Conclusions}

FIB tomography was used to visualize and quantify the grains and precipitates in 7075-T651 aluminum alloys in $3 \mathrm{D}$, after localization of a region of interest via $\mathrm{x}$-ray microtomography (XRM). Using correlative tomography, we were able to obtain combined information on size and distribution of inclusions, grains, and precipitates. Using FIB tomography, a large dataset was obtained for quantification of precipitates in $3 \mathrm{D}$. The shape of the recrystallized grains was approximately spherical with sphericity and maximum Feret diameter values of $0.73 \pm 0.05$ and $2.9 \pm 1.38 \mu \mathrm{m}$, respectively. The volume, feret diameter and aspect ratio of the precipitates on the grain boundaries were found to be higher than the precipitates within grains. It was also shown in 3D that inclusions can act as heterogeneous nucleation sites for precipitation and can therefore have a significant impact on the distribution of precipitates in the alloy. 


\section{Acknowledgements}

The authors are grateful for financial support from the Office of Naval Research (ONR) under Contract No. N000141010350 (Dr. W. Mullins and Dr. A. K. Vasudevan, Program Manager). AM acknowledges the support of Luke Hunter and Susan Candell from Carl Zeiss X-ray Microscopy in the acquisition and analysis of the XRM dataset. We also acknowledge Dr. Ken Lagarec of Fibics and Dr. Lorenz Lechner from Carl Zeiss for the FIB-SEM tomography acquisition and reconstruction.

\section{References}

[1] AlHazaa A, Khan TI, Haq I. Transient liquid phase (TLP) bonding of A17075 to Ti-6Al-4V alloy. Mater Charact 2010; 61: 312-17.

[2] Starke Jr. EA, Staley JT. Application of modern aluminum alloys to aircraft. Progress in Aerospace Sci 1996; 32: 131-72.

[3] Speidel MO. Stress corrosion cracking of aluminum alloys. Metall Trans A 1975; 6: 631-51.

[4] Li JF, Peng ZW, Li CX, Jia ZQ, Chen WJ, Zheng ZQ. Mechanical properties, corrosion behaviors and microstructures of 7075 aluminium alloy with various aging treatments. T Nonferr Metal Soc 2008; 18: 755-62.

[5] Singh SS, Schwartzstein C, Williams JJ, Xiao X, De Carlo F, Chawla N. 3D microstructural characterization and mechanical properties of constituent particles in Al 7075 alloys using x-ray synchrotron tomography and nanoindentation. J Alloy Comp 2014; 602: 163-74.

[6] Ma K, Wen H, Hu T, Topping TD, Isheim D, Seidman DN, et al. Mechanical behavior and strengthening mechanisms in ultrafine grain precipitation-strengthened aluminum alloy, Acta Mater 2014; 62: 141-55.

[7] Viana F, Pinto AMP, Santos HMC, Lopes AB. Retrogression and re-ageing of 7075 aluminium alloy: microstructural characterization. J Mater Process Tech 1999; 92-93: 54-59. 
[8] Liu JZ, Chen JH, Yuan DW, Wu CL, Zhu J, Cheng ZY, Fine precipitation scenarios of $\mathrm{AlZnMg}(\mathrm{Cu})$ alloys revealed by advanced atomic-resolution electron microscopy study Part I: Structure determination of the precipitates in $\mathrm{AlZnMg}(\mathrm{Cu})$ alloys, Mater Charact 2015; 99: $277-$ 86.

[9] Liu JZ, Chen JH, Liu ZR, Wu CL, Fine precipitation scenarios of $\mathrm{AlZnMg}(\mathrm{Cu}$ ) alloys revealed by advanced atomic-resolution electron microscopy study Part II: Fine precipitation scenarios in $\mathrm{AlZnMg}(\mathrm{Cu})$ alloys, Mater Charact 2015; 99: 142-49.

[10] Goswami R, Lynch S, Holroyd NJH, Knight SP, Holtz RJ. Evolution of grain boundary precipitates in Al 7075 upon aging and correlation with stress corrosion cracking behavior. Metall Mater Trans A 2013; 44: 1268-78.

[11] Sun XY, Zhang B, Lin HQ, Zhou Y, Sun L, Wang JQ, et al. Correlations between stress corrosion cracking susceptibility and grain boundary microstructures for an Al-Zn-Mg alloy. Corros Sci 2013; 77: 103-12.

[12] Adler PN, Delasi R. Calorimetric studies of 7000 series aluminum alloys: II. Comparison of 7075, 7050 and RX720 alloys. Metall Trans A 1977; 8: 1185-90.

[13] Garcia-Garcia AL, Dominguez-Lopez I, Lopez-Jimenez L, Barceinas-Sanchez JDO. Comparative quantification and statistical analysis of $\eta$ ' and $\eta$ precipitates in aluminum alloy AA7075-T651 by TEM and AFM. Mater Charact 2014; 87: 116-24.

[14] Gjonnes J, Simensen CJ. An electron microscope investigation of the microstructure in an aluminium-zinc-magnesium alloy. Acta Metall 1970; 18: 881-90.

[15] Li XZ, Hansen V, Gjonnes J, Wallenberg LR, HREM study and structure modeling of the ๆ' phase, the hardening precipitates in commercial Al-Zn-Mg alloys. Acta Mater 1999; 47: 265159.

[16] Ringer SP, Hono K. Microstructural evolution and age hardening in aluminium alloys: Atom probe field-ion microscopy and transmission electron microscopy studies. Mater Charact 2000; 44: 101-31.

[17] Deschamps A, Brechet Y. Nature and distribution of quench-induced precipitation in an AlZn-Mg-Cu alloy. Scripta Mater 1998; 39: 1517-22. 
[18] Engdahl T, Hansen V, Warren PJ, Stiller K, Investigation of fine scale precipitates in Al-ZnMg alloys after various heat treatments. Mat Sci Eng A 2002; 327: 59-64.

[19] Stiller K, Warren PJ, Hansen V, Angenete J, Gjonnes J, Investigation of precipitation in an $\mathrm{Al}-\mathrm{Zn}-\mathrm{Mg}$ alloy after two-step ageing treatment at $100^{\circ} \mathrm{C}$ and $150^{\circ} \mathrm{C}$. Mat Sci Eng 1999; 270: 55-63.

[20] Werenskiold JC, Deschamps A, Brechet Y. Characterization and modeling of precipitation kinetics in an Al-Zn-Mg alloy. Mat Sci Eng A 2000; 293: 267-74.

[21] Birbilis N, Cavanaugh M, Buchheit RG, Harlow DG, Wei RP. Understanding damage accumulation upon AA7075-T651 used in airframes from a microstructural point of view. In: Deason D, Boyer RR, editors. Application of materials science to military systems, Materials Science and Technology, Pittsburg: 2005, P. 57-67.

[22] Zhao YH, Liao XZ, Jin Z, Valiev RZ, Zhu YT. Microstructures and mechanical properties of ultrafine grained $7075 \mathrm{Al}$ alloy processed by ECAP and their evolutions during annealing. Acta Mater 2004; 52: 4589-99.

[23] Delasi R, Adler PN. Calorimetric studies of 7000 series aluminum alloys: I. matrix precipitate characterization of 7075. Metall Trans A 1977; 8: 1177-83.

[24] Totten GE, MacKenzie DS. Handbook of Aluminum: Alloy Production and Materials Manufacturing. vol. 2. New York: Marcel Dekker, Inc; 2003.

[25] H. Au, Pitting and crack initiation in high strength aluminum alloys for aircraft applications. Ph.D. thesis. Massachusetts Institute of Technology; 1996.

[26] Feng AH, Chen DL, Ma ZY. Microstructure and cyclic deformation behavior of a frictionstir-welded 7075 Al alloy. Metall Mater Trans A 2010; 41: 957-71.

[27] Porter DA, Easterling KE, Sherif M. Phase Transformations in Metals and Alloys. 3rd ed. Florida: CRC Press; 2009.

[28] Miller MK, Kenik EA. Atom probe tomography: A technique for nanoscale characterization. Microsc Microanal 2004; 10 336-41. 
[29] Midgley PA, Dunin-Borkowski RE. Electron tomography and holography in materials science. Nat Mater 2009; 8: 271-80.

[30] Bansal RK, Kubis A, Hull R, Fitz-Gerald JM. High-resolution three-dimensional reconstruction: A combined scanning electron microscope and focused ion-beam approach. J Vac Sci Technol B 2006; 24: 554-61.

[31] Sidhu RS, Chawla N. Three-dimensional microstructure characterization of $\mathrm{Ag}_{3} \mathrm{Sn}$ intermetallics in Sn-rich solder by serial sectioning. Mater Charact 2004; 52: 225-30.

[32] Stock SR. X-ray microtomography of materials. Int Mater Rev 1999; 44: 141-64.

[33] Singh DRP, Chawla N, Shen YL. Focused ion beam (FIB) tomography of nanoindentation damage in nanoscale metal/ceramic multilayers. Mater Charact 2010; 61: 481-88.

[34] Dudek MA, Chawla N. Mechanisms for Sn whisker growth in rare earth-containing Pb-free solders. Acta Mater 2009: 57: 4588-99.

[35] Yazzie KE, Williams JJ, Phillips NC, De Carlo F, Chawla N. Multiscale microstructural characterization of Sn-rich alloys by three dimensional (3D) X-ray synchrotron tomography and focused ion beam (FIB) tomography. Mater Charact 2012: 70: 33-41.

[36] Uchic MD, Groeber MA, Dimiduk DM, Simmons JP. 3D microstructural characterization of nickel superalloys via serial-sectioning using a dual beam FIB-SEM. Scripta Mater 2006; 55: 23 28.

[37] Holzapfel C, Schaf W, Marx M, Vehoff H, Mucklich F. Interaction of cracks with precipitates and grain boundaries: understanding crack growth mechanisms through focused ion beam tomography. Scripta Mater 2007; 56: 697-00.

[38] Merkle AP, Lechner L, Steinbach A, Gelb J, Kienle M, Phaneuf MW, et al. Automated correlative tomography using XRM and FIB-SEM to span length scales and modalities in 3D materials. Microsc Anal 2014; 28: S10-13.

[39] http://www.zeiss.com/microscopy/en_de/products/microscope-software/atlas-5.html

[40] Singh SS, Guo E, Xie H, Chwala N. Mechanical properties of intermetallic inclusions in Al 7075 alloys by micropillar compression. Intermetallics 2015; 62: 69-75. 
[41] Singh SS, Williams JJ, Stannard TJ, Xiao X, De Carlo F, Chawla N, Measurement of localized corrosion rates at inclusion particles in AA7075 by in situ three dimensional (3D) Xray synchrotron tomography, Corros Sci 2016; 104: 330-35.

[42] Weickert J, Anisotropic Diffusion in Image Processing, Teubner, Stuttgart, Germany, 1998.

[43] Maire E, Grenier JC, Babot D, Baldacci A, Klocker H, Bigot A. Quantitative 3D characterization of intermetallic phases in an Al-Mg industrial alloy by X-ray microtomography. Scripta Mater 2006; 55: 123-26.

[44] Connolly BJ, Horner DA, Fox SJ, Davenport AJ, Padovani C, Zhou S, et al. X-ray microtomography studies of localised corrosion and transitions to stress corrosion cracking. Mater Sci Tech 2006; 22: 1076-85.

[45] Padilla E, Jakkali V, Jiang L, Chawla N. Quantifying the effect of porosity on the evolution of deformation and damage in Sn-based solder joints by X-ray microtomography and microstructure-based finite element modeling. Acta Mater 2012; 60: 4017-26.

[46] Williams JJ, Flom Z, Amell AA, Chawla N, Xiao X, De Carlo F. Damage evolution in SiC particle reinforced $\mathrm{Al}$ alloy matrix composites by $\mathrm{x}$-ray synchrotron tomography. Acta Mater 2010; 58: 6194-05.

[47] Jiang L, Chawla N, Pacheco M, Noveski V. Three-dimensional (3D) microstructural characterization and quantification of reflow porosity in Sn-rich alloy/copper joints by $\mathrm{x}$-ray tomography. Mater Charact 2011; 62: 970-75.

[48] Root JMM. Structure evolution and recrystalization in 7xxx series aluminum alloys. Master's thesis. Washington State University; 2010.

[49] Abbaschian R, Abbaschian L, Reed-Hill RB. Physical Metallurgy Principles. 4th ed. Stamford: Cengage Learning; 2008.

[50] Marlaud T, Deschamps A, Bley F, Lefebvre W, Baroux B. Influence of alloy composition and heat treatment on precipitate composition in $\mathrm{Al}-\mathrm{Zn}-\mathrm{Mg}-\mathrm{Cu}$ alloys. Acta Mater 2010; 58: $248-60$. 


\section{List of Tables}

Table 1. Quantitative analysis of grains in Al 7075 alloys

Table 2. Quantitative analysis of precipitates in AA 7075-T651

Table 3. Comparison of the size and shape of precipitates on grain boundaries and inside the grains. 


\section{List of Figures}

Figure 1. Microstructure of Al 7075 alloys in decreasing length scales (a) optical surface image showing grains, (b) X-ray tomography image (2D virtual slice of 3D volume) showing inclusions, and (c) grains and nanoscale precipitates visible in FIB-SEM slice.

Figure 2. 2D slice of AA7075 obtained from FIB tomography showing grains, an inclusion, a pore associated with the inclusion, and precipitates.

Figure 3. (a) Whole 3D volume showing grains, an inclusion and precipitates, and (b) cropped $3 \mathrm{D}$ volume showing pore associated with the $\mathrm{Mg}_{2} \mathrm{Si}$ inclusion.

Figure 4. Step wise segmentation of grain, pore and inclusion (a) original gray scale image, (b) gray scale image after anisotropic diffusion filter in ImageJ, (c) application of Livewire technique to a grain in MIMICS, and (d) corresponding segmented grain. Figure (e) shows the magnified version of the grain in (c). Figs. (f) and (g) are the images before and after application of anisotropic diffusion filter of the blue region in Fig. (a).

Figure 5. Step wise segmentation of precipitates (a) gray scale image obtained from FIB tomography, (b) image after application of band-pass filter, (c) image with very high signal-tonoise ratio after anisotropic diffusion filter, and (d) binary white and black image from thresholding in ImageJ.

Figure 6. 3D rendering of (a) grains/inclusion/pore, (b) precipitates, and (c) combined grains and precipitates.

Figure 7. (a) Volume distribution of grains, and (b) sphericity distribution of grains.

Figure 8. (a) Volume distribution, (b) aspect ratio, and (c) Feret diameter distributions of precipitates in AA7075. 
Figure 9. 3D rendering of (a) grains with precipitates, (b) precipitates on grain boundaries, and (c) precipitates inside grains.

Figure 10. Magnified images of (a) grain boundary precipitates, and (b) precipitates inside the grains, showing that the size of grain boundary precipitates is typically higher than those inside the grains.

Figure 11. Precipitates size and shape distributions on grain boundaries and inside the grains (a) volume distribution, (b) Feret diameter, and (c) aspect ratio.

Figure 12. 3D rendering of (a) inclusion/pore with precipitates, (b) precipitates on inclusion boundary, and (c) precipitates inside inclusion.

Figure 13. Precipitate size and shape distributions on interface between grains and an inclusion (a) volume distribution, (b) Feret diameter, and (c) aspect ratio. 
Table 1.

\begin{tabular}{|c|c|c|}
\hline & Mean & Max \\
\hline Volume $\left(\mu^{3}\right)^{3}$ & 4.3 (Skewness: 1.5$)$ & 18.2 \\
\hline Max. Feret diameter $(\mu \mathrm{m})$ & $2.9 \pm 1.38$ & 6.3 \\
\hline Sphericity & $0.73 \pm 0.05$ & 0.84 \\
\hline
\end{tabular}

Table 2.

\begin{tabular}{|c|c|c|c|}
\hline & Mean & Max & Skewness \\
\hline Volume (nm $\left.{ }^{3}\right)$ & $4.2 \times 10^{5}$ & $3.7 \times 10^{7}$ & 11.61 \\
\hline Max. Feret diameter (nm) & 131.26 & 3356 & 7.50 \\
\hline Aspect ratio & 2.24 & 13.58 & 2.19 \\
\hline
\end{tabular}


Table 3.

\begin{tabular}{|c|c|c|c|c|c|c|}
\hline & \multicolumn{2}{|c|}{ Mean } & \multicolumn{2}{c|}{ Max } & \multicolumn{2}{c|}{ Skewness } \\
\hline & $\begin{array}{c}\text { Inside } \\
\text { grains }\end{array}$ & GB & $\begin{array}{c}\text { Inside } \\
\text { grains }\end{array}$ & GB & $\begin{array}{c}\text { Inside } \\
\text { grains }\end{array}$ & GB \\
\hline Volume (nm ) & $2.9 \times 10^{5}$ & $7.7 \times 10^{5}$ & $9.5 \times 10^{6}$ & $3.7 \times 10^{7}$ & 6.83 & 6.90 \\
\hline $\begin{array}{c}\text { Max. Feret } \\
\text { diameter (nm) }\end{array}$ & 114.4 & 145.6 & 923 & 3356 & 2.67 & 6.60 \\
\hline \begin{tabular}{c} 
Aspect ratio \\
\hline
\end{tabular} & 2.35 & 2.72 & 7.62 & 13.58 & 1.91 & 2.06 \\
\hline
\end{tabular}




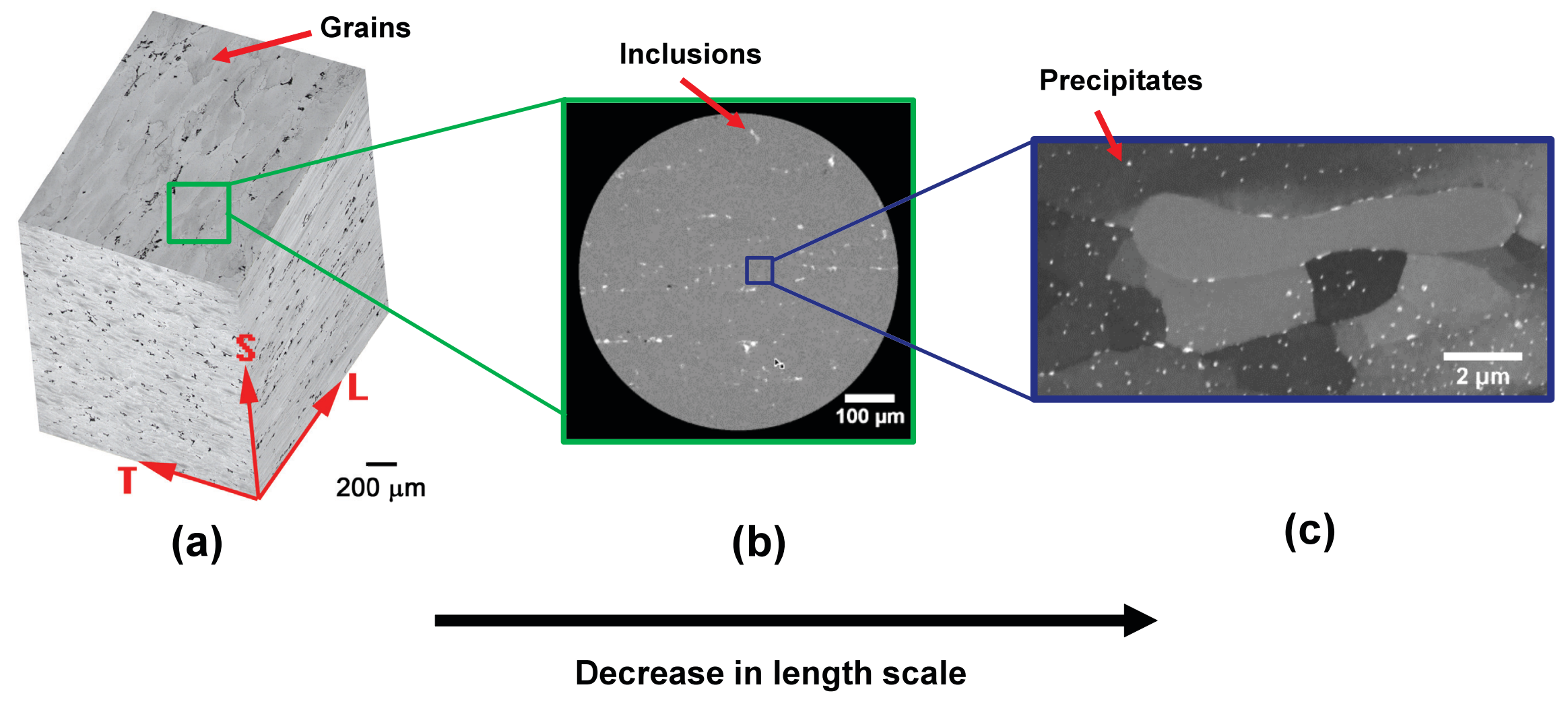

Figure 1. 


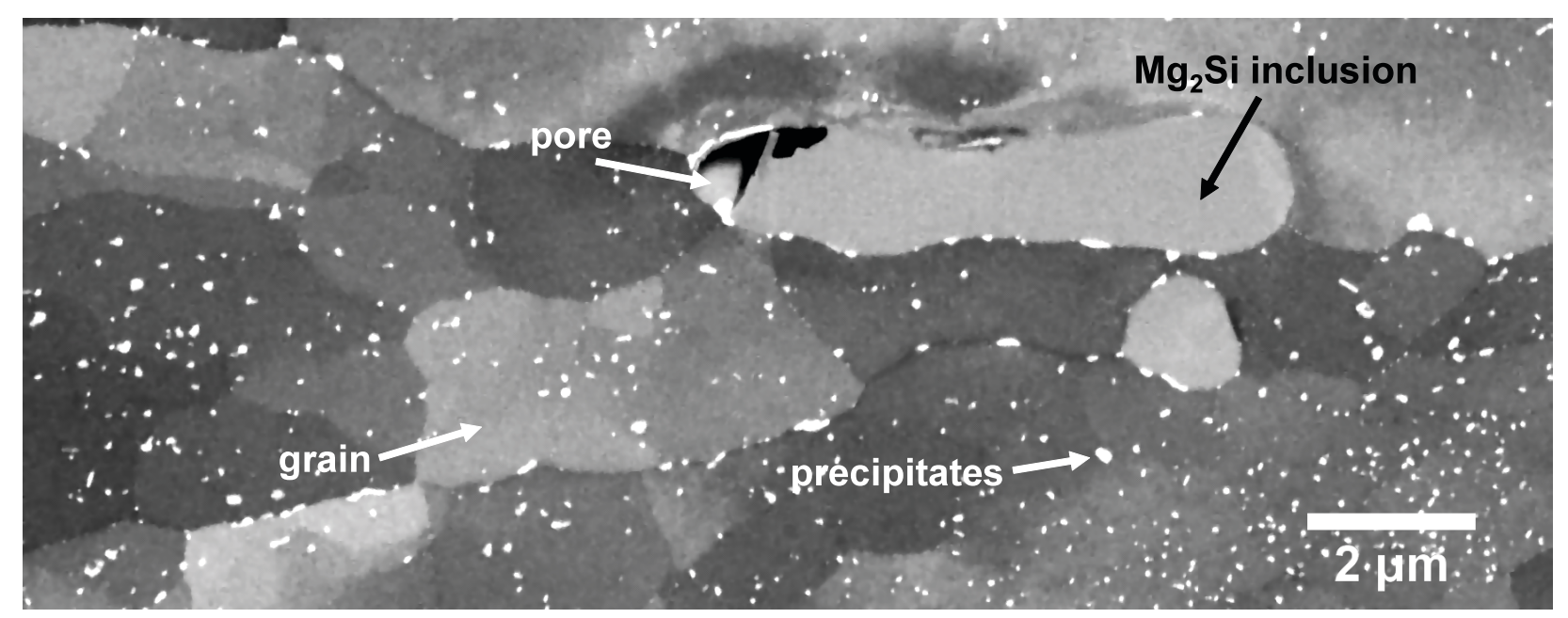

Figure 2. 

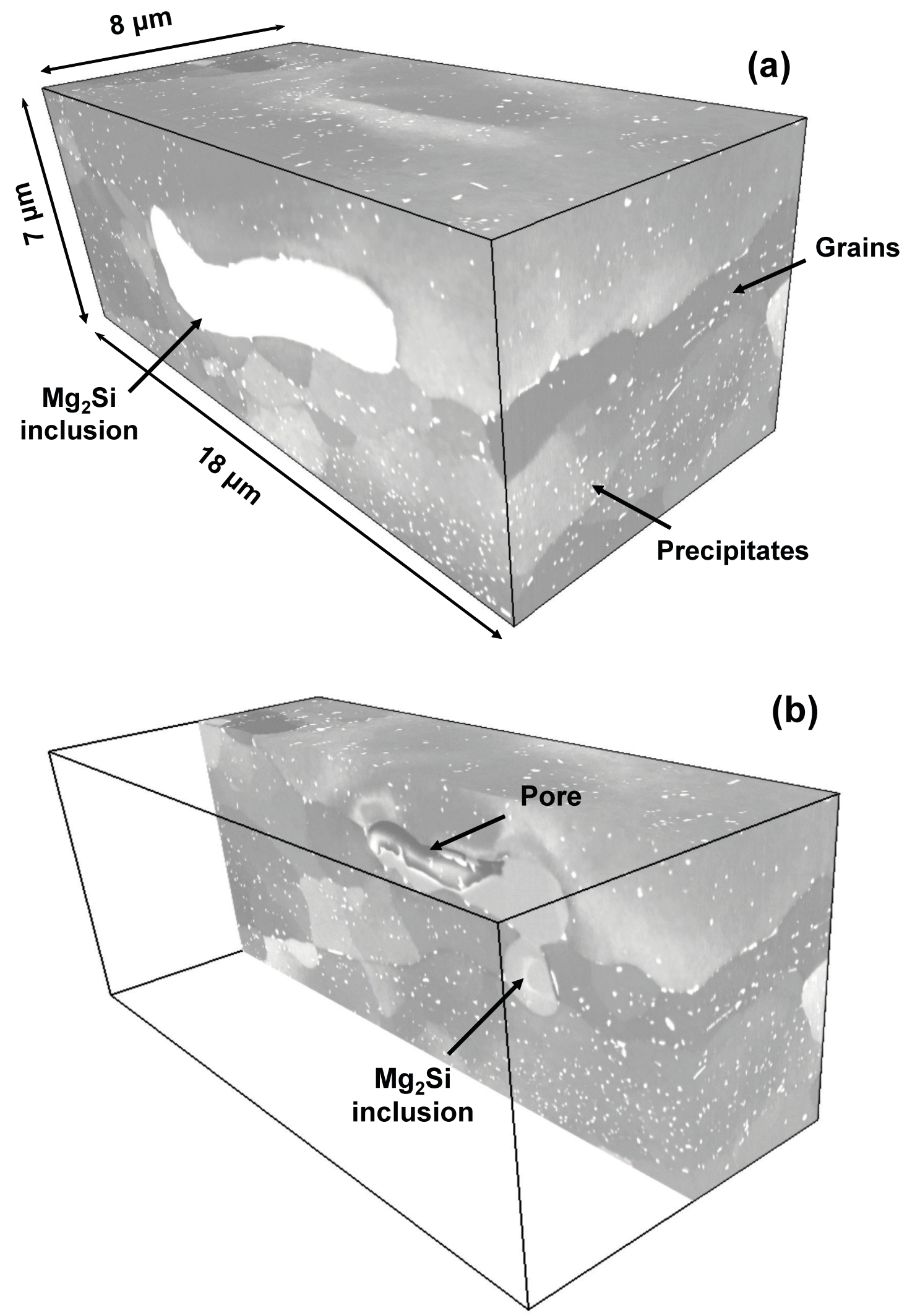

Figure 3. 

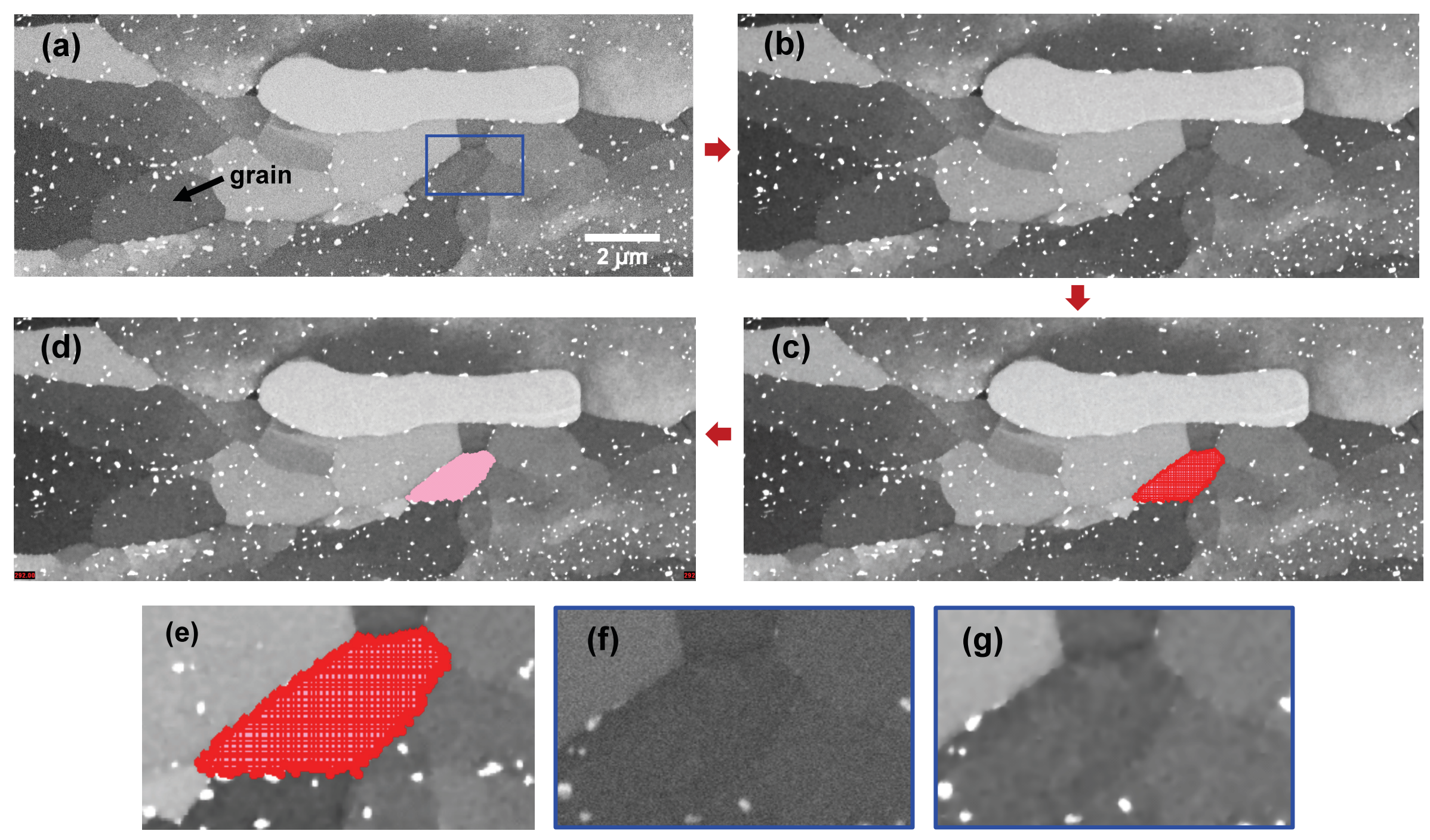

Figure 4. 

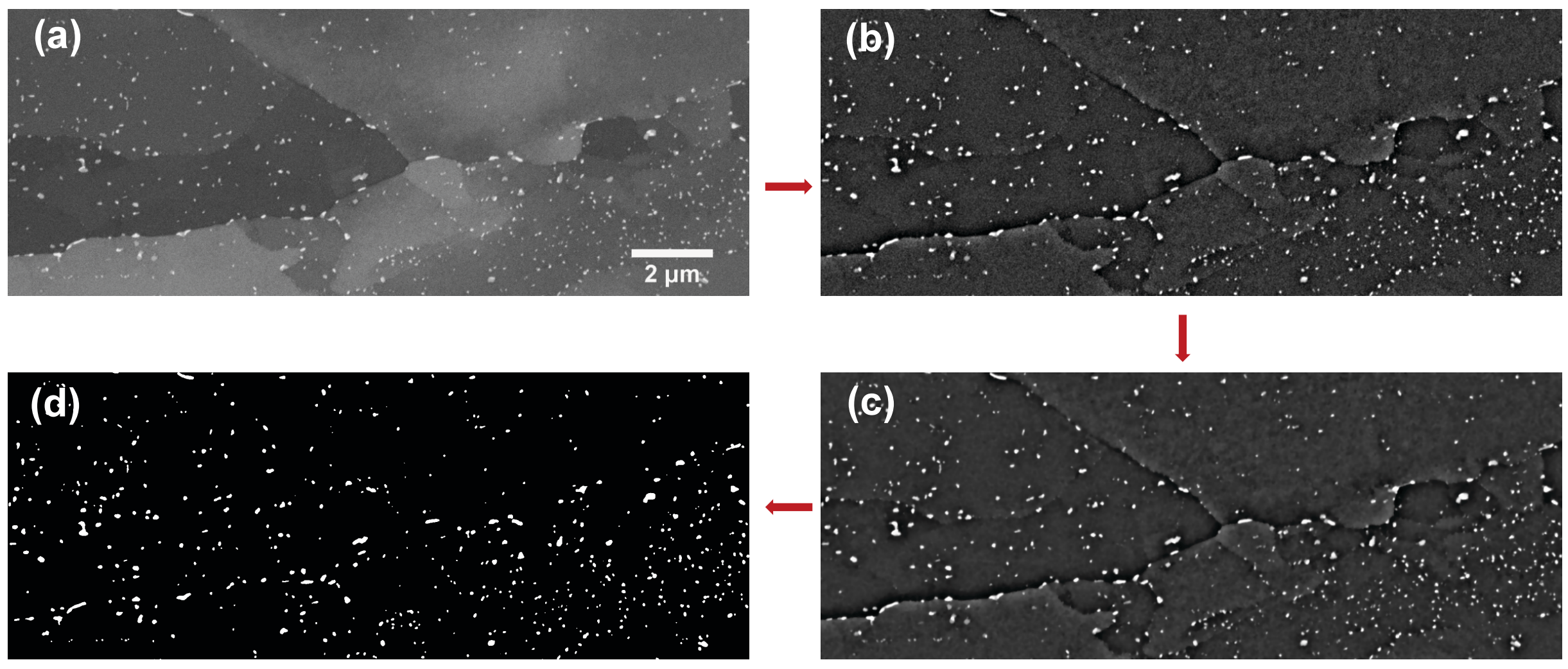

Figure 5. 


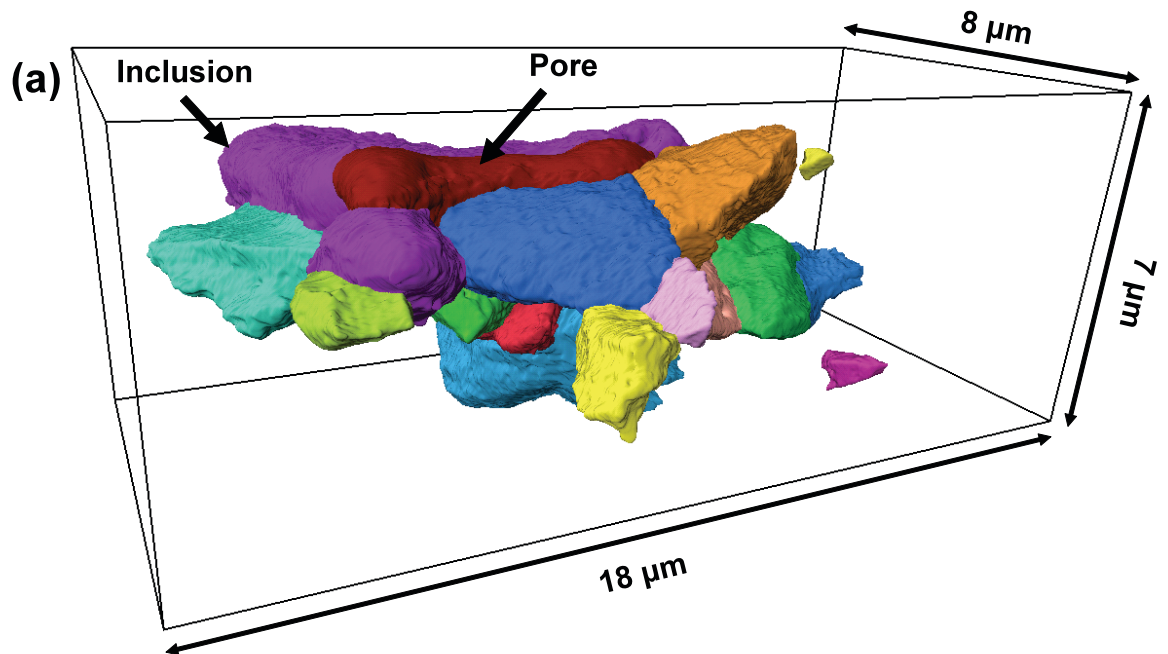

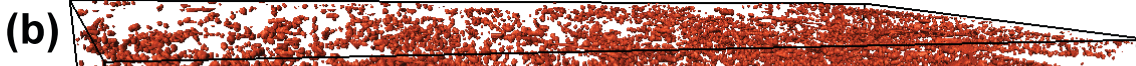

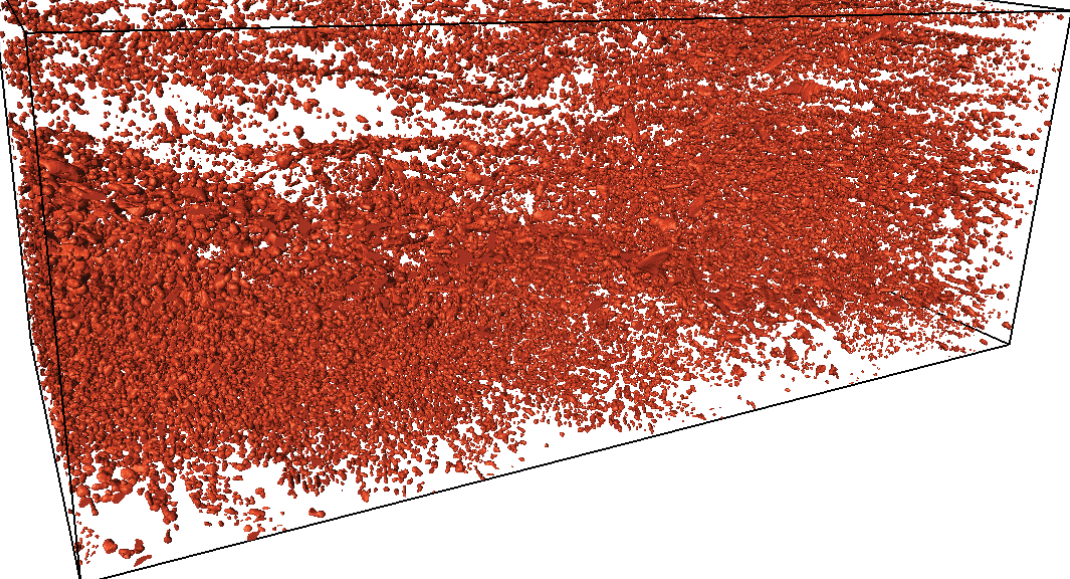

(c)

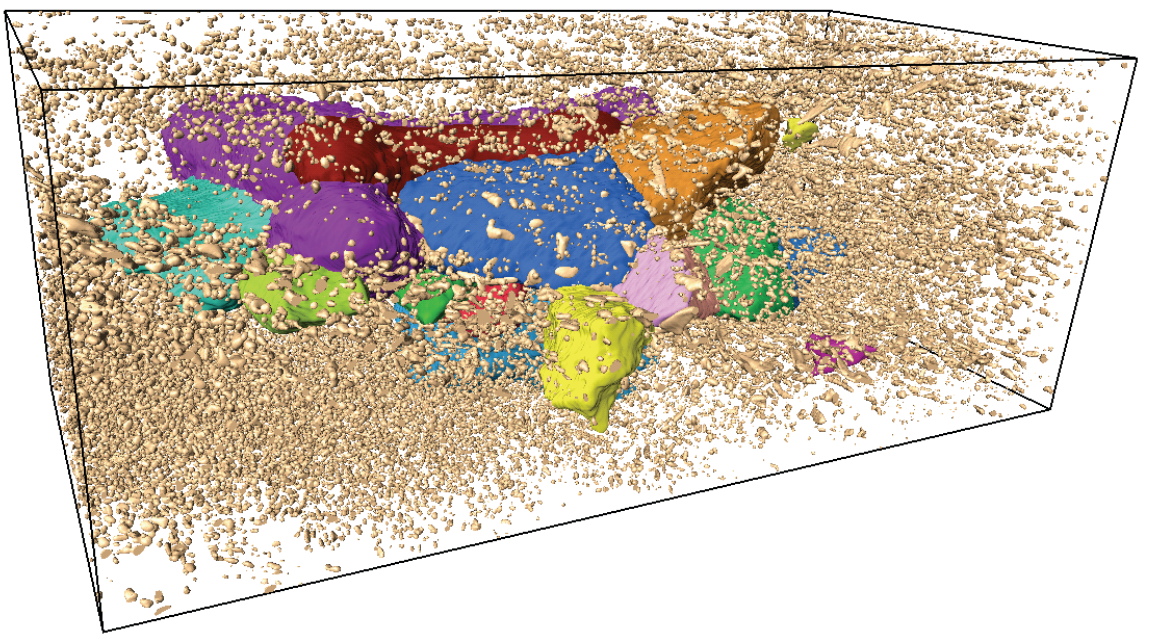

Figure 6. 

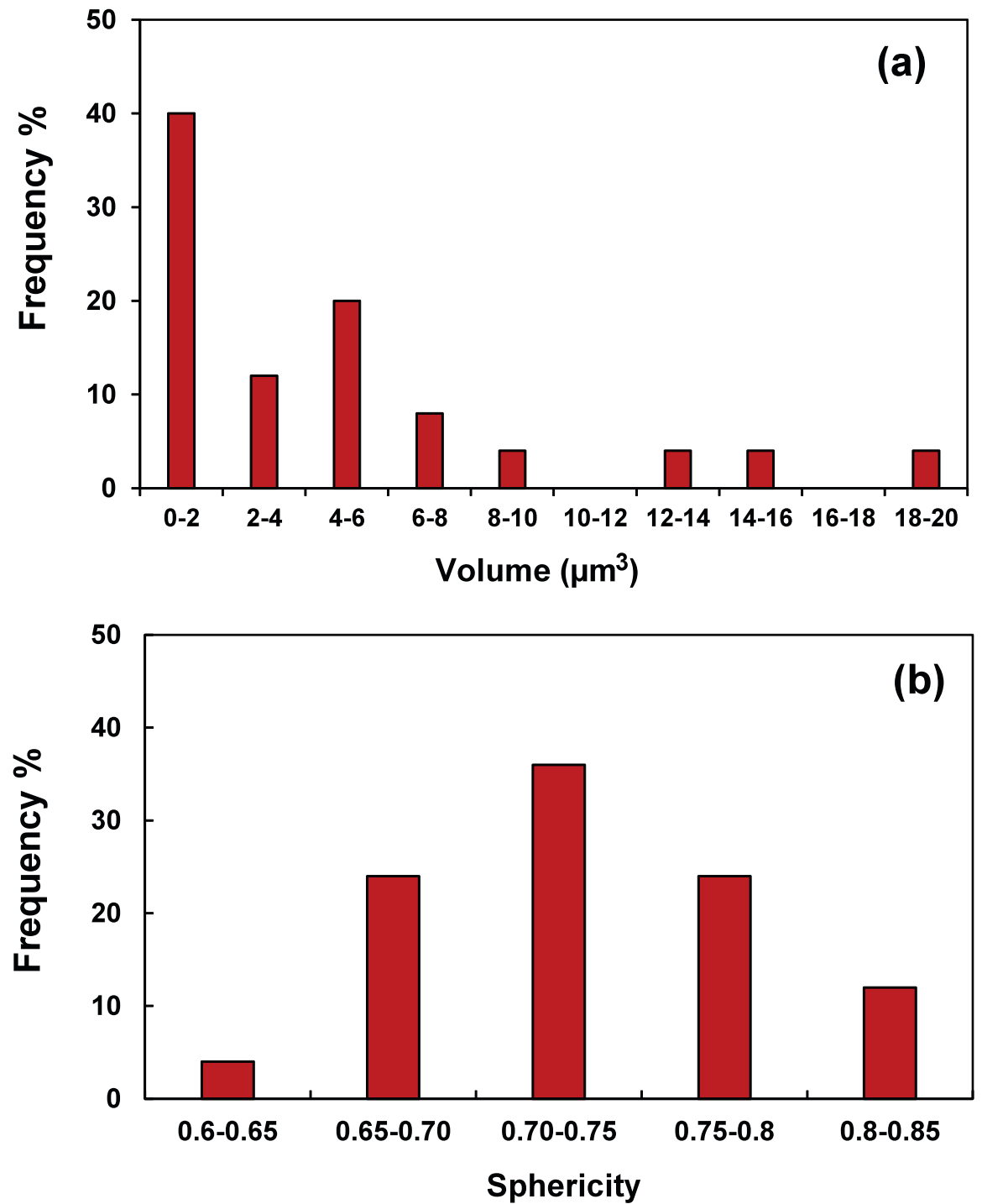

Figure 7. 


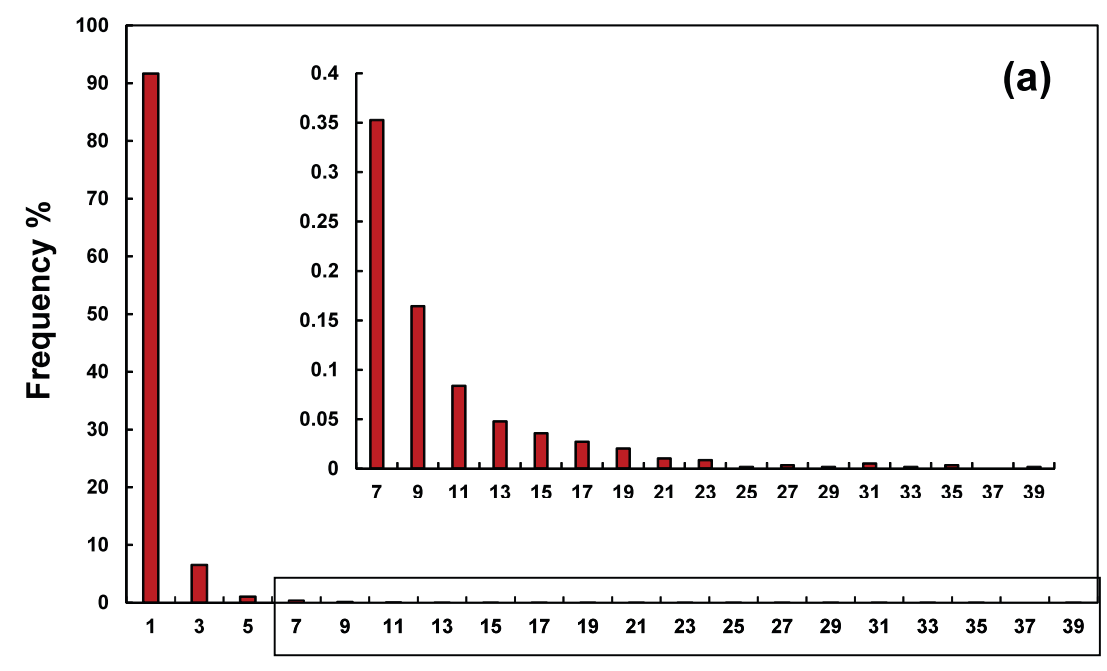

Volume $\left(\mathrm{nm}^{3}\right) \times 10^{6}$
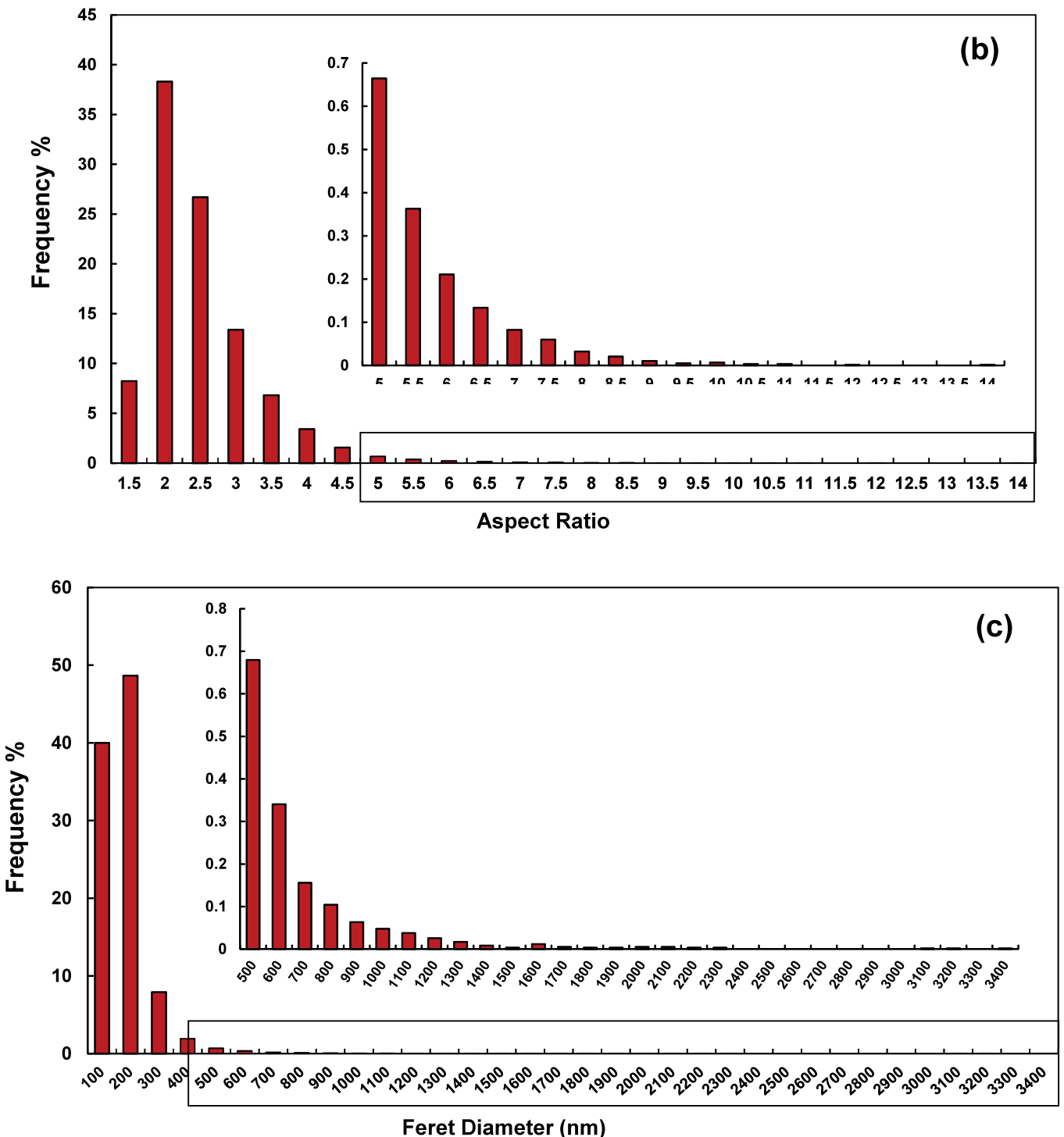

Figure 8. 

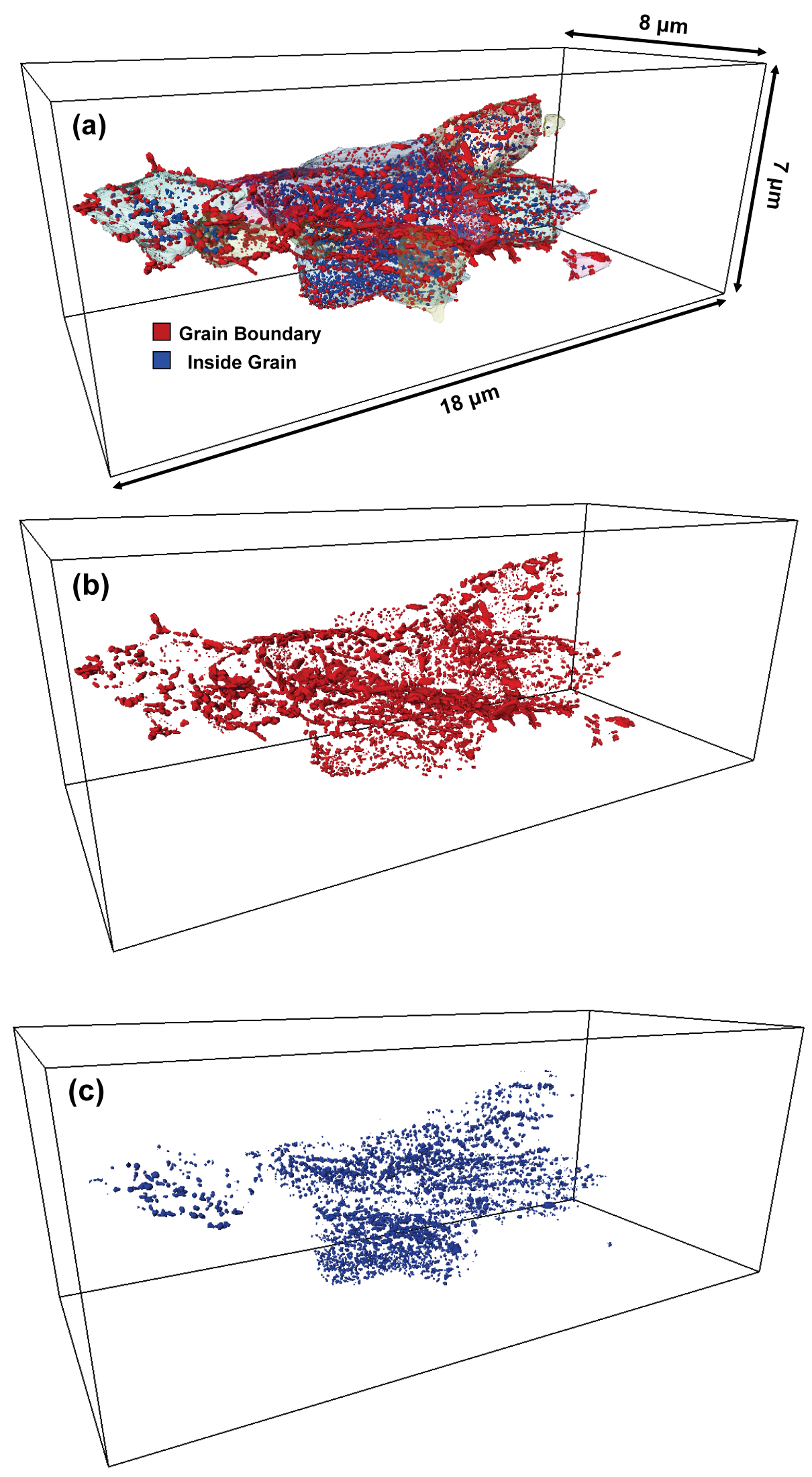

Figure 9. 

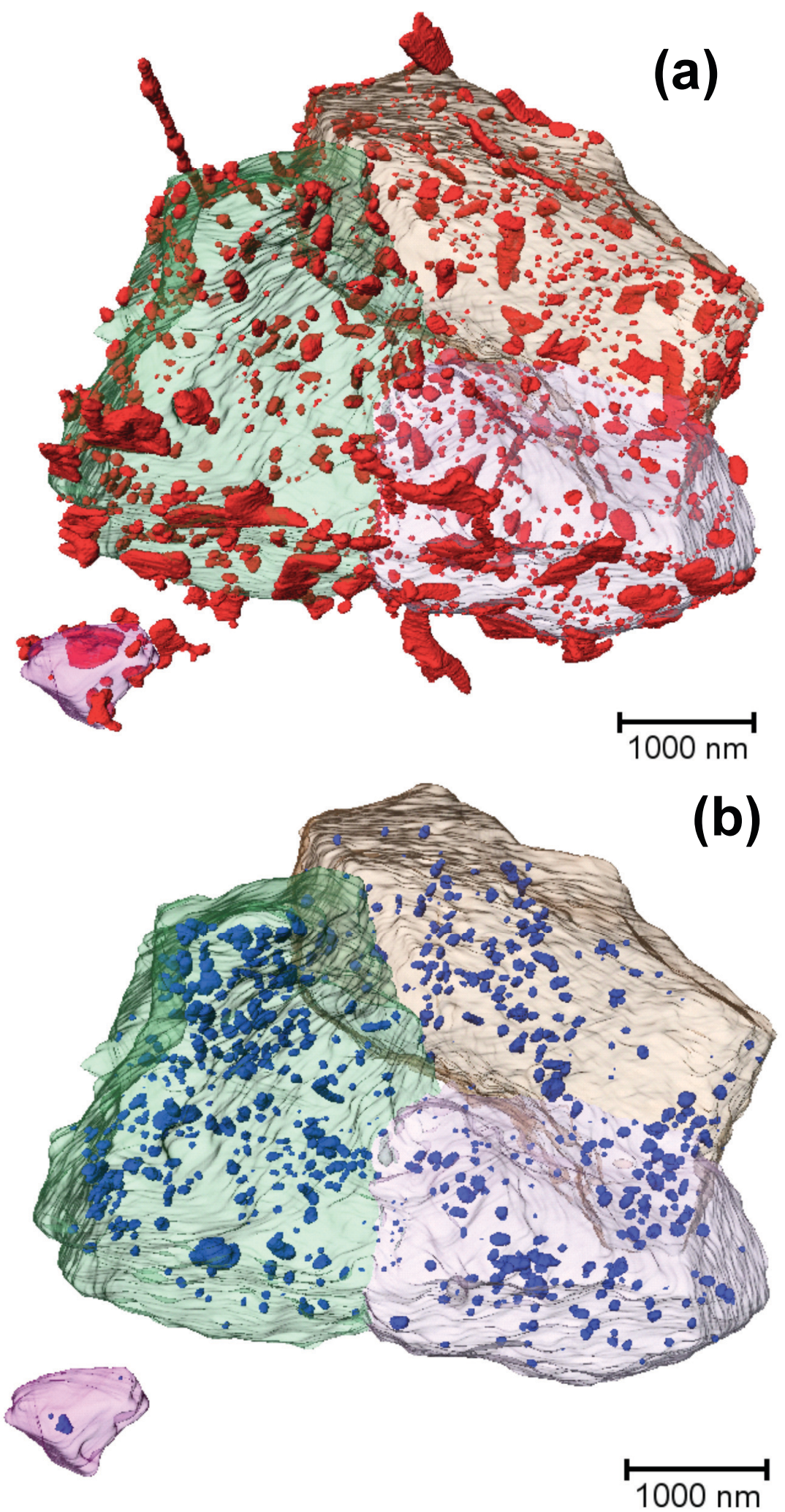

Figure 10. 

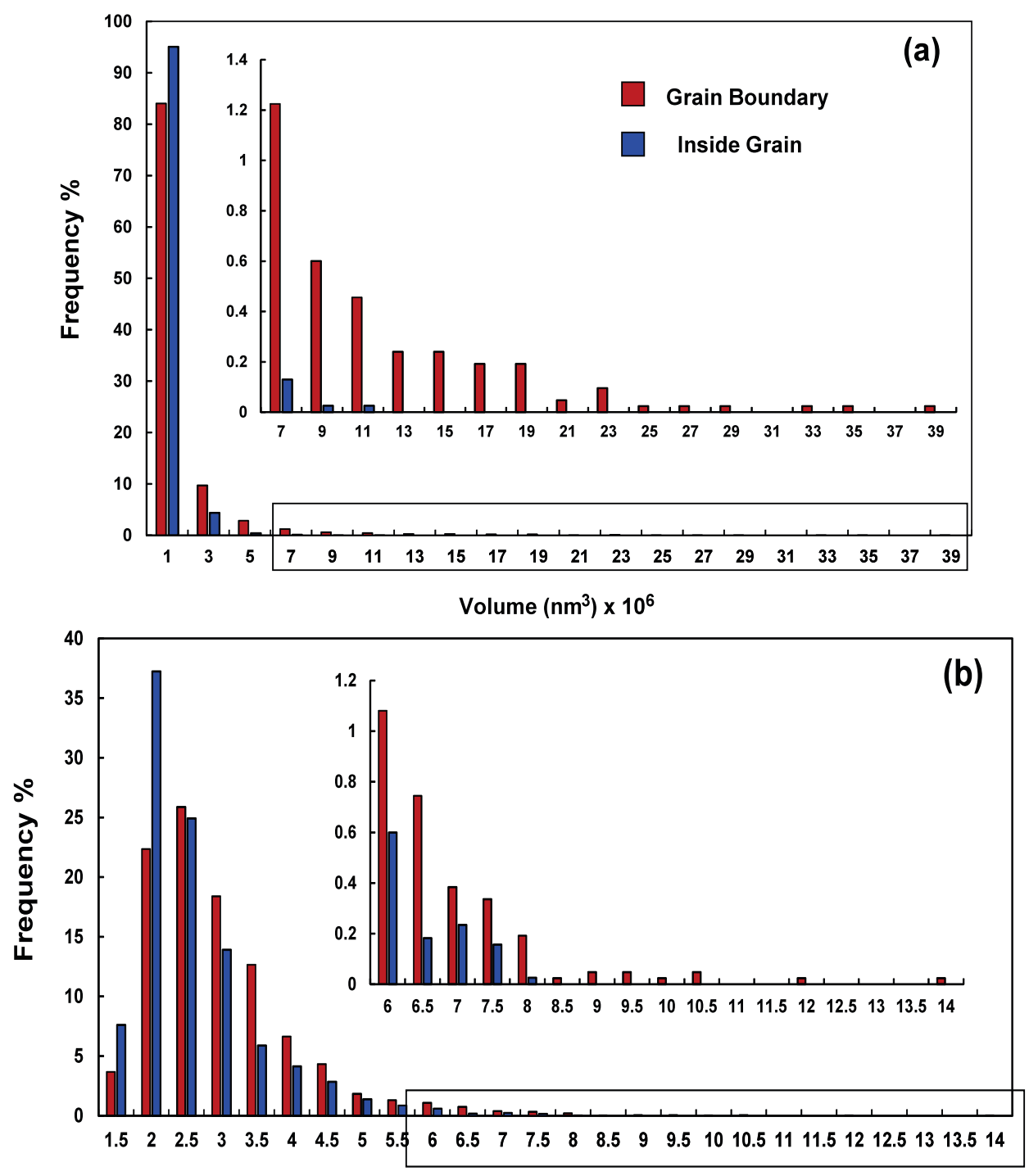

Aspect Ratio

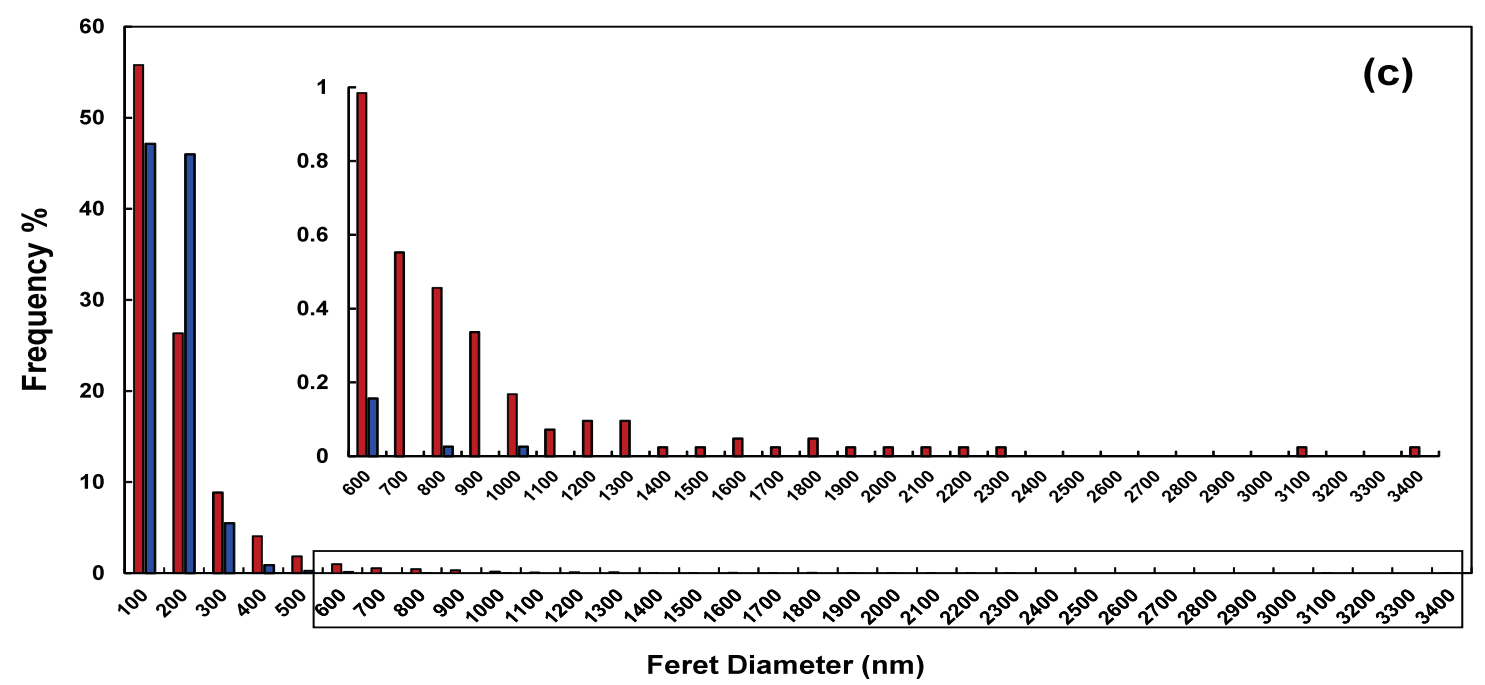

Figure 11. 

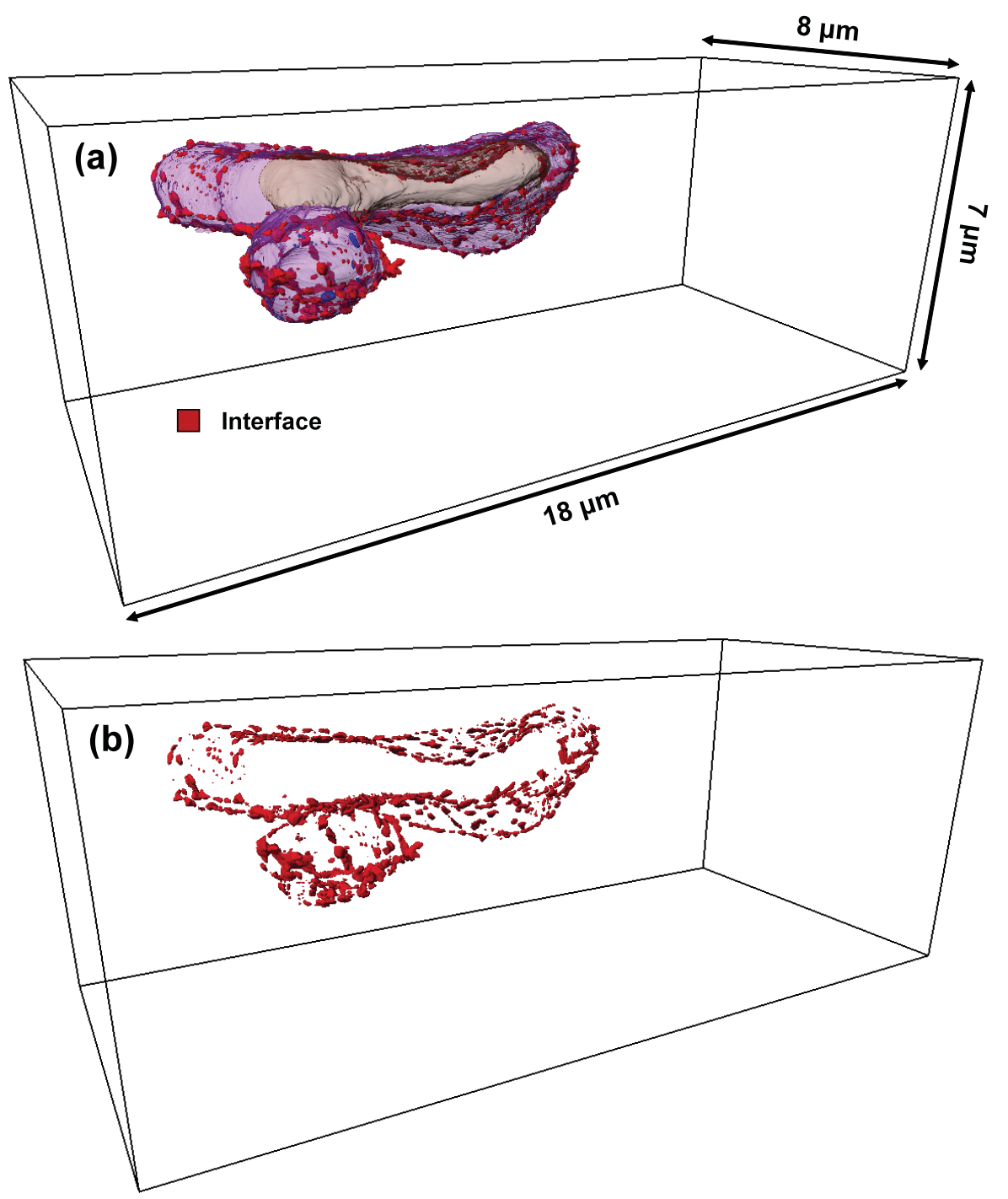

Figure 12. 

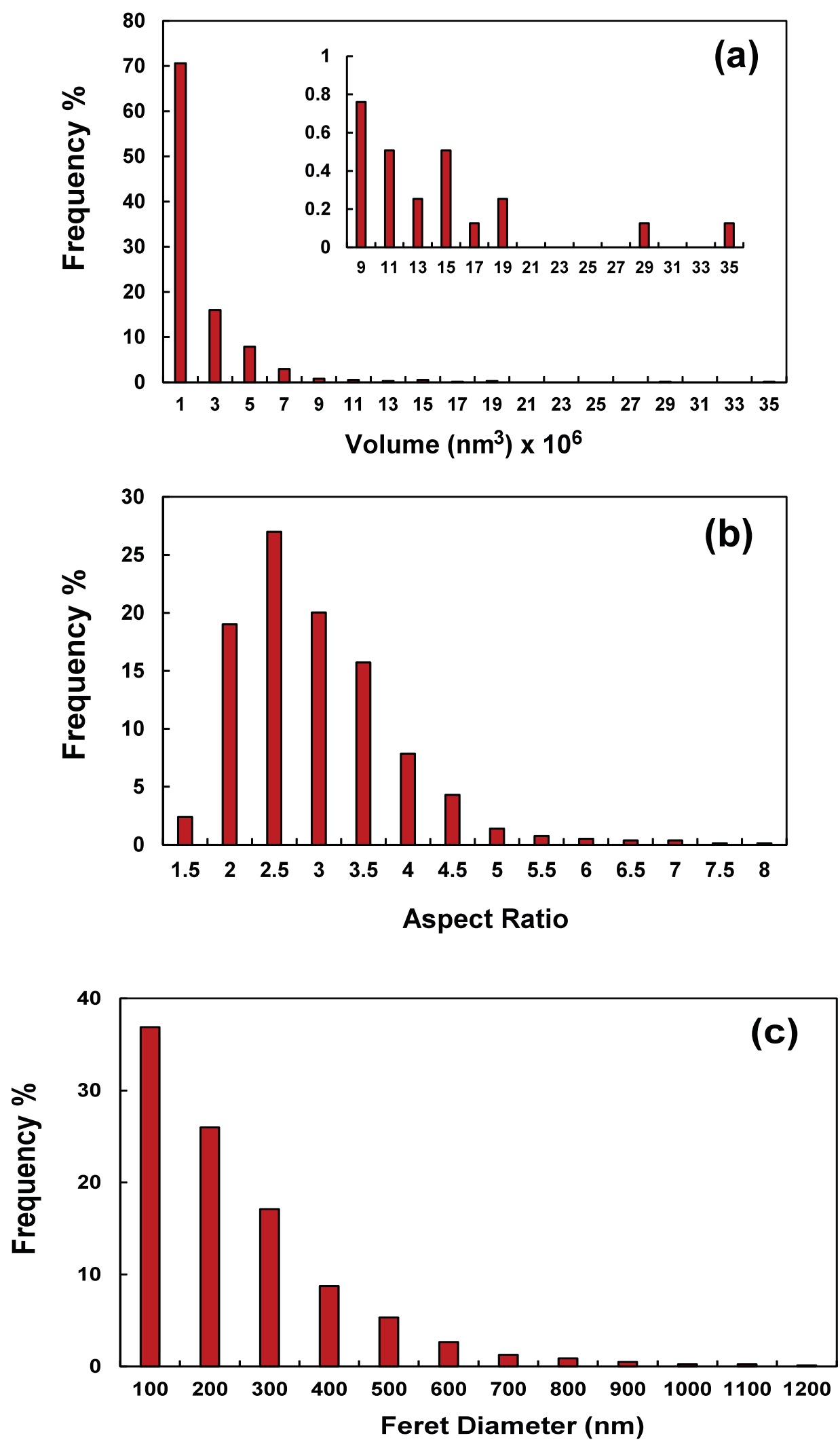

Figure 13. Precipitate size and shape distributions on interface between grains and an inclusion (a) volume distribution, (b) Feret diameter, and (c) aspect ratio. 